\title{
Age-related variation in sexual behaviours among heterosexual men residing in Brazil, Mexico and the USA
}

\author{
Euna M August, ${ }^{1}$ Ellen Daley, ${ }^{2}$ Jeffrey Kromrey, ${ }^{3}$ Julie Baldwin, ${ }^{4}$ \\ Nancy Romero-Daza, ${ }^{5}$ Jorge Salmeron, ${ }^{6}$ Eduardo Lazcano-Ponce, ${ }^{7}$ \\ Luisa L Villa, ${ }^{8}$ Carol A Bryant, ${ }^{9}$ Anna R Giuliano ${ }^{10}$
}

For numbered affiliations see end of article.

\section{Correspondence to Dr Anna R Giuliano, H Lee Moffitt Cancer Center and Research Institute, Department of Cancer Epidemiology, 12902 Magnolia Drive MRC-CANCONT, Tampa, FL 33612, USA; anna.giuliano@moffitt.org}

Received 14 December 2012 Revised 8 August 2013 Accepted 15 August 2013 Published Online First 7 October 2013
CrossMark

To cite: August EM, Daley E,
Kromrey J, et al. J Fam Plann
Reprod Health Care
2014:40:261-269.

\section{ABSTRACT}

Objective To compare the prevalence of demographic characteristics and sexual behaviours across age groups and to estimate their significance in predicting sexual risk factors by age cohort. Methods This cohort study examined sexually transmitted infection (STI) prevalence among heterosexual men in Brazil, Mexico and the USA ( $N=3047)$. Participants completed a sexual risk factor questionnaire and were tested for chlamydia, gonorrhoea, syphilis and genital herpes. We examined sexual risk in the study population through a composite measure of STI positivity by age cohort (young: 18-30 years; middle-aged: 31-44 years; older: 45-70 years). Multivariable logistic regression models were used to generate adjusted odds ratios (AORs) and 95\% confidence intervals ( $\mathrm{Cls}$ ).

Results We found that STI positivity varied significantly by age group among heterosexual men by a number of covariates. In younger men, having more advanced education had a protective effect ( 16 years: $A O R=0.37,95 \% \mathrm{Cl} 0.15-0.92$ ), whereas higher numbers of sexual partners elevated the risk for STIs (20-49 partners: $\mathrm{AOR}=2.06,95 \% \mathrm{Cl} 1.04-4.06 ; \geq 50$ partners: $A O R=4.33,95 \% \mathrm{Cl} 1.74-10.76)$. Middle-aged men who were black $(A O R=1.64,95 \% \mathrm{Cl} 1.10$ 2.42) and divorced/separated/widowed ( $A O R=1.91,95 \%$ Cl 1.21-3.02) had an increased risk for a positive STI test. Among older men, a younger age at first vaginal sexual encounter (AOR=3.75, 95\% Cl 1.45-9.74) and a history of exchanging sex for money or drugs heightened STI risk (AOR=2.30, 95\% CI 1.0-5.04).

Conclusions These findings demonstrate that age-related life experiences among heterosexual men influence sexual risk and STI transmission. This topic warrants further investigation to support the development and implementation of targeted interventions that may potentially reduce adverse sexual health outcomes.

\section{Key message points}

- This study provides further evidence that key risk factors for sexually transmitted infection (STI) transmission among men include paid sexual encounters, higher numbers of lifetime sexual partners, and early sexual debut.

- This study underscores the importance of research regarding sexual behaviours and risk among heterosexual men.

- There is a need for added public health research and interventions to address STI risk and transmission among men across the lifespan.

- Additional research is needed to provide an enhanced contextual understanding of sexual behaviours and decision-making among men.

\section{INTRODUCTION}

Most research on the prevalence of risky sexual behaviours has focused on subgroups of men thought to be at high risk for sexually transmitted infections (STIs), including men who have sex with men and substance-using males. ${ }^{1-3}$ Due to this focus, research examining factors associated with heterosexual men's acquisition of STIs has been limited. ${ }^{1-5}$ Furthermore, studies assessing sexual behaviours among heterosexuals have focused primarily on women. ${ }^{1-5}$ Thus, there is a need for research on STI risk factors for heterosexual men who do not belong to groups considered to be at 'high risk'.

Similarly, while numerous studies have investigated sexual behaviour by gender 
and race/ethnicity, most research on men's sexual risk practices has focused on younger populations, including adolescents and young adults. ${ }^{6-8}$ The focus on younger adults may be attributed to the higher prevalence and incidence of STIs, as well as higher rates of disease transmission, within this population. ${ }^{9-11}$ However, in recent years, HIV/AIDS cases among older adults have been on the rise. ${ }^{12-14}$ Furthermore, sexual risk-taking has been found to be frequent within older age cohorts. ${ }^{13} 15$

Overall, there is a paucity of data on sexual risktaking among various age cohorts of heterosexual men, including middle-aged and older men. In this study, we examined the prevalence and correlates of sexual behaviours by age cohort within a crossnational sample of adult, heterosexual, sexually active men in Brazil, Mexico and the USA. The purpose of this study was two-fold: (1) to compare the prevalence of different demographic characteristics and sexual behaviours across age groups and (2) to estimate the significance of multiple demographic and behavioural variables in predicting sexual risk by age cohort.

\section{METHODS}

\section{Study design and sample}

This was a cross-sectional analysis of baseline data collected within a cohort study. The study sample was drawn from men who were enrolled in the anal human papillomavirus (HPV) in Men (HIM) Study from June 2005 to December $2009(N=4074)$. The HIM Study is a cross-national, natural history study that explores factors associated with HPV prevalence and incidence among men in Sao Paulo, Brazil, Cuernavaca, Mexico and Tampa, Florida in the USA. Data collected from this study were used to investigate sexual risk behaviour across the lifespan. Study recruitment in Brazil is facilitated through media advertising and a centre for urogenital care in Sao Paulo, while in Mexico participants are recruited through the public health system, local factories and military personnel in Cuernavaca. In the USA, recruitment efforts involve print and radio advertising within a local university, as well as in the greater metropolitan area of Tampa.

The study population for the parent study consisted of men who met the following inclusion criteria: (a) aged 18-70 years; (b) residents of one of the three study sites; (c) no reports of prior diagnosis with penile or anal cancers; (d) no report of symptoms of or treatment for an STI; (e) not currently participating in an HPV vaccine study; (f) no history of HIV/AIDS; (g) no history of imprisonment, homelessness or drug treatment during the past 6 months; and (h) willingness to comply with 10 scheduled study visits conducted every 6 months over a 4-year period with no plans to relocate during study implementation. For the present analysis, we restricted the study population to heterosexual men, excluding any men who reported prior sexual activity with a male partner, including oral and/or anal intercourse $(n=596)$. We also excluded men who were not sexually active $(n=431)$, defined as those who did not report ever having vaginal intercourse. This resulted in a final sample size of 3047 men. The elimination process that resulted in our study population is depicted in Figure 1.

\section{Risk factor questionnaire}

A comprehensive health questionnaire was administered to study participants at enrolment. This instrument assesses socio-demographic characteristics, alcohol and tobacco use, sun exposure, history of STIs, circumcision status, sexual history and contraceptive practices. A full description of the questionnaire has been published elsewhere. ${ }^{16}{ }^{17}$ The original instrument was written in English and was later translated into the primary language of each of the survey sites (i.e. Portuguese in Brazil; Spanish in Mexico) and backtranslated to English to ensure accuracy in the assessment process. A test-retest reliability study of the instrument was previously conducted in all three languages utilised in the study and yielded high reliability coefficients for all variables (intraclass correlation coefficient $\geq 0.85$ ). ${ }^{16}$ The questionnaire required approximately 20 minutes to complete and was administered in participating clinics using Computer-Assisted Self-Interviewing (CASI). Study administrators were available to provide assistance to participants with computer problems or issues with questions in the survey. For each survey item, participants were given the option to refuse to answer. These responses were treated as missing observations, as the values are unknown.

\section{Testing for STIs}

Upon study enrolment, men who provided consent for participation underwent a clinical examination. At the time of survey administration, participants were tested for chlamydia, gonorrhoea, herpes simplex virus 2 (HSV2; also known as genital herpes) and syphilis. Urine specimens $(20-30 \mathrm{ml})$ were collected in urine collection cups free of any preservatives for testing to detect gonorrhoea and chlamydia RNA by transcription-mediated amplification. A $2 \mathrm{ml}$ urine specimen was transferred into the GenProbe specimen transport tube within 24 hours of collection before being assayed. Sera were tested for syphilis infection by Rapid Plasma Reagin. Positive results were confirmed with the more specific fluorescent treponemal antibody absorption (FTA-ABS) test. A reactive FTA-ABS test confirms the presence of treponemal antibodies but does not indicate the stage or presence of active infection. Sera were also tested for HSV2 by immunoassay with the IgG Type Specific Antibody $\left(\right.$ HerpeSelect ${ }^{\circledR}$ ) test. Pre-wetted Dacron applicators were used to collect biological samples from the 


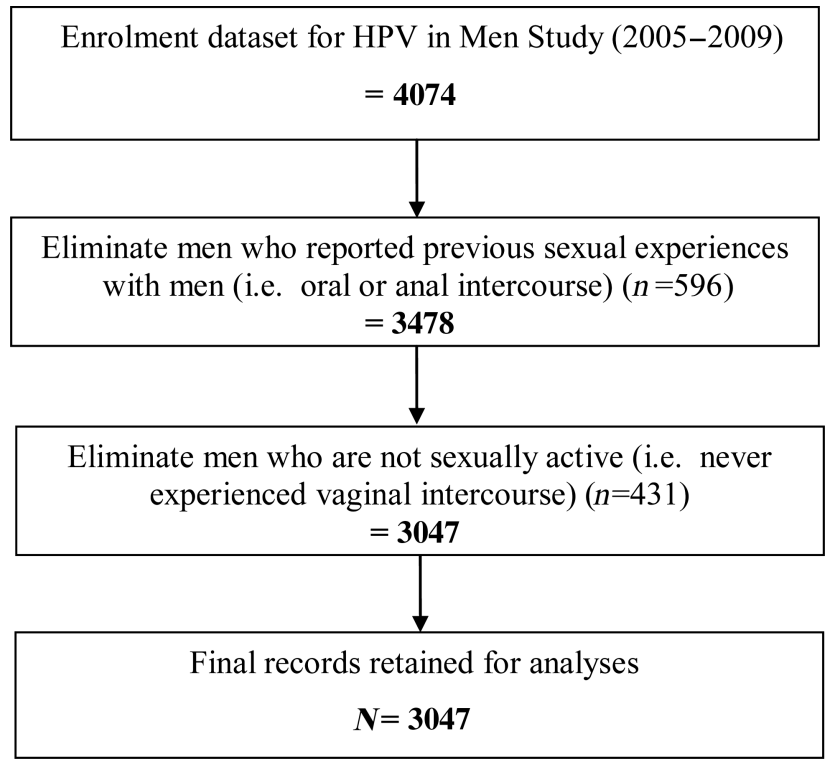

Figure 1 Flow chart of exclusion process for the study.

external genitalia of participants, including the glans penis/coronal sulcus, the penile shaft and the scrotum, for HPV testing. Before DNA extraction, the three samples were combined to produce one DNA extract per participant and combined to produce a single clinical specimen. HPV testing of the combined DNA extract was conducted using polymerase chain reaction for amplification of a fragment of the HPV L1 gene. A participant was considered positive for HPV if he tested positive for at least one genotype. Participants with positive test results for any STI were offered treatment at no cost.

\section{Variables}

We compared participants by age cohort on a range of demographic variables and sexual behaviours found to affect the likelihood of STI transmission, based on biologic plausibility and a review of the literature. The age cohorts were defined as 18-30, 31-44 and 4570 years (i.e. young adults, middle-aged adults and older adults, respectively). Demographic variables included in the analysis were: country of residence (Brazil, Mexico, USA); self-identified race (White, Black, Asian/Pacific Islander, American Indian, Mixed); Hispanic (Yes, No); marital status (single, married, cohabitating, divorced/separated/widowed); educational level $(<12,12,13-15,16, \geq 17$ years); self-reported circumcision status (Yes, No); and current smoking status (Yes, No). All men included in the sample were defined as heterosexual (i.e. no reported history of sexual intercourse with men) with a history of sexually activity (i.e. ever experiencing vaginal sexual intercourse). Multiple variables regarding men's sexual behaviours were incorporated in the analysis, including history of anal and oral sexual activity, age at first vaginal sex, lifetime number of female sexual partners, if they had ever paid for sexual intercourse (i.e. exchanged sex for money or drugs) and condom use within the recent past (i.e. up to 6 months preceding survey administration).

The primary outcome of interest was sexual risk. While a standardised means of assessing sexual risk has not been established in the literature, the prevalence and occurrence of STIs have been identified as critical outcome measures of sexual risk. ${ }^{18-20}$ Therefore, sexual risk was quantified through the composite variable for STI test results. This composite variable was constructed to denote a positive test result for the presence of at least one of the four STIs tested for in this study (i.e. chlamydia, gonorrhoea, genital herpes and syphilis). The composite variable for sexual risk excluded HPV, as its prevalence is much higher relative to other STIs; within the study population, approximately half of the men are positive for HPV. Therefore, the exclusion of HPV ensured that the study assessed risky behaviour associated with general STI prevalence, rather than HPV prevalence (which has previously been published as part of the parent study). ${ }^{21-23}$

\section{Statistical analysis}

Since all variables were categorical, differences in the distribution of demographic characteristics and sexual behaviours were examined by age cohort and tested using the Chi square $\left(\chi^{2}\right)$ test. Logistic regression was conducted to examine the association between demographic factors and sexual behaviours and the likelihood of testing positive for an STI. Odds ratios, together with their corresponding 95\% confidence limits, were generated to assess the association of the predictor variables and sexual risk. We also stratified the regression analyses by age cohort to evaluate group 
differences. Variables included in the multivariate model were those found to be statistically significant in the bivariate analysis. All hypotheses tests were twotailed with a Type I error rate set at 5\%. SAS (V.9.2) (SAS Institute, Cary, NC, USA) was used for data management and for all data manipulations. This investigation was approved by the Institutional Review Board of the University of South Florida.

\section{RESULTS}

The study sample consisted of 3047 men, aged 1870 years, with a mean age of 32.3 years [standard deviation (SD) \pm 11.1 ; median $=31.0$ years]. A comparison of selected demographic characteristics by age cohort is presented in Table 1 . The study sample consisted predominately of young adult men, with half being aged $18-30$ years $(n=1523 ; 50.0 \%)$ and more than one-third aged $31-44$ years $(n=1131 ; 37.1 \%)$. Roughly one-third of the sample resided in each of the three study sites, Brazil (29.1\%), Mexico (35.3\%) and the USA (35.6\%). Young adult males were more likely to be single, whereas middle-aged and older adults (45-70 years) were more likely to be married. Younger and older males were more likely to have some advanced/college level education, but middle-aged males were more likely to have lower levels of education. Although the majority of men in the study sample were uncircumcised $(60.7 \%)$, the

Table 1 Demographic characteristics by age cohort*

\begin{tabular}{|c|c|c|c|c|c|}
\hline Demographic characteristic & $\begin{array}{l}\text { Total } \\
(N=3047) \\
{[n(\%)]}\end{array}$ & $\begin{array}{l}18-30 \text { years } \\
(N=1523) \\
{[n(\%)]}\end{array}$ & $\begin{array}{l}31-44 \text { years } \\
(N=1131) \\
{[n(\%)]}\end{array}$ & $\begin{array}{l}45-70 \text { years } \\
(N=393) \\
{[n(\%)]}\end{array}$ & $p$ \\
\hline Country of residence & & & & & $<0.0001$ \\
\hline Brazil & $888(29.1)$ & $352(23.1)$ & $419(37.1)$ & $117(29.8)$ & \\
\hline Mexico & $1075(35.3)$ & $443(29.1)$ & $490(43.3)$ & $142(36.1)$ & \\
\hline USA & $1084(35.6)$ & $728(47.8)$ & $222(19.6)$ & $134(34.1)$ & \\
\hline Race & & & & & $<0.0001$ \\
\hline White & $1330(43.7)$ & $723(47.5)$ & $428(37.8)$ & $179(45.6)$ & \\
\hline Black & $425(14.0)$ & $202(13.3)$ & $160(14.2)$ & $63(16.0)$ & \\
\hline Asian/Pacific Islander & $87 \quad(2.9)$ & 70 (4.6) & 16 (1.4) & $1(0.3)$ & \\
\hline American Indian/Alaskan & $55(1.8)$ & $20(1.3)$ & $28(2.5)$ & $7(1.8)$ & \\
\hline Mixed & $1002(32.9)$ & $415(27.3)$ & $450(39.8)$ & $137(34.9)$ & \\
\hline Unknown/refused & $148 \quad(4.9)$ & $93(6.1)$ & 49 (4.3) & $6(1.5)$ & \\
\hline Hispanic & & & & & $<0.0001$ \\
\hline Yes & $1423(46.7)$ & $633(41.6)$ & $616(54.5)$ & $174(44.3)$ & \\
\hline No & $1599(52.5)$ & $881(57.9)$ & $501(44.3)$ & $217(55.2)$ & \\
\hline Unknown/refused & $25(0.8)$ & $9(0.6)$ & $14(1.2)$ & $2(0.5)$ & \\
\hline Marital status & & & & & $<0.0001$ \\
\hline Single & $1303(42.8)$ & $1063(69.8)$ & $200(17.7)$ & $40 \quad(10.2)$ & \\
\hline Married & $1082(35.5)$ & $244(16.0)$ & $611(54.0)$ & $227(57.8)$ & \\
\hline Cohabitating & $380(12.5)$ & $168(11.0)$ & $174(15.4)$ & $38 \quad(9.7)$ & \\
\hline Divorced/separated/widowed & $273(9.0)$ & $42 \quad(2.8)$ & $143(12.6)$ & $88(22.4)$ & \\
\hline Unknown/refused & $9(0.3)$ & $6 \quad(0.4)$ & $3(0.3)$ & $0 \quad(0.0)$ & \\
\hline Educational level (years) & & & & & $<0.0001$ \\
\hline$<12$ & $650(21.3)$ & $231(15.2)$ & $314(27.8)$ & $105(26.7)$ & \\
\hline 12 & $808(26.5)$ & $415(27.3)$ & $322(28.5)$ & $71(18.1)$ & \\
\hline $13-15$ & $813(26.7)$ & $556(36.5)$ & $169(14.9)$ & $88(22.4)$ & \\
\hline 16 & $584(19.2)$ & $270(17.7)$ & $227(20.1)$ & $87(22.1)$ & \\
\hline$\geq 17$ & $184(6.0)$ & $47 \quad(3.1)$ & 97 (8.6) & $40(10.2)$ & \\
\hline Unknown/refused & $8(0.3)$ & $4 \quad(0.3)$ & $2(0.2)$ & $2(0.5)$ & \\
\hline Circumcision status & & & & & $<0.0001$ \\
\hline Yes & $1197(39.3)$ & $718(47.1)$ & $317(28.0)$ & $162(41.2)$ & \\
\hline No & $1850(60.7)$ & $805(52.9)$ & $814(72.0)$ & $231(58.8)$ & \\
\hline Current smoking status & & & & & 0.3758 \\
\hline Yes & $713(23.4)$ & $356(23.4)$ & $275(24.3)$ & $82(20.9)$ & \\
\hline No & $2328(76.4)$ & $1162(76.3)$ & $855(75.6)$ & $311(79.1)$ & \\
\hline Unknown/refused & $6 \quad(0.2)$ & $5 \quad(0.3)$ & $1(0.1)$ & $\begin{array}{ll}0 & (0.0)\end{array}$ & \\
\hline
\end{tabular}

*Percentages may not total to 100 due to rounding. 
levels varied by age cohort, with young adults having the highest proportion of circumcision $(47.1 \%)$ and middle-aged adults having the lowest (28.0\%).

Table 2 provides information on the participants' self-reported sexual behaviours with women by age cohort. The majority of men (43.8\%), across age cohorts, reported their first experience of vaginal intercourse between the ages of 15 and 17 years. The mean age of the men's first experience of vaginal sexual intercourse was 16.9 years $(\mathrm{SD} \pm 3.2$; median $=17.0$ years). The majority of men $(90.0 \%)$ reported ever having performed and/or experienced oral sex, and half (49.7\%) reported ever having insertive anal sex. The frequency of oral sex was observed to decrease with increasing age (18-30 years: $92.9 \%$; $31-44$ years: $89.3 \% ; 45-70$ years: $80.9 \%)$. However, men within the middle-aged category reported the highest rates of anal intercourse $(57.3 \%)$. Middle-aged adults also reported the highest proportion of experiences exchanging sexual intercourse for money or drugs (13.9\%). When asked about condom use with vaginal intercourse during the 3-6 months period prior to the survey, the most frequent response across age cohorts was 'never' (36.9\%). The absence of condom use with vaginal sex increased with increasing age, with approximately one-quarter of young men $(24.4 \%)$ reporting never using them compared to more than half of older men $(55.7 \%)$. Overall, the largest proportion of participants reported two to nine lifetime female sexual partners (45.3\%); however, the variance in numbers varied by age cohort, with reported lifetime numbers being more concentrated in this range among young adults and being more widely distributed among middle-aged and older men.

The risk estimates for the model of association with a positive test for an STI in this study sample by age cohort are presented in Table 3. Relative to the oldest

Table 2 Self-reported sexual behaviours by age cohort*

\begin{tabular}{|c|c|c|c|c|c|}
\hline Sexual behaviour & $\begin{array}{l}\text { Total } \\
(N=3047) \\
{[n(\%)]}\end{array}$ & $\begin{array}{l}18-30 \text { years } \\
(N=1523) \\
{[n(\%)]}\end{array}$ & $\begin{array}{l}31-44 \text { years } \\
(N=1131) \\
{[n(\%)]}\end{array}$ & $\begin{array}{l}45-70 \text { years } \\
(N=393) \\
{[n(\%)]}\end{array}$ & $p$ \\
\hline \multicolumn{5}{|l|}{ Age at first vaginal sex (years) } & $<0.0001$ \\
\hline$\leq 14$ & $551(18.1)$ & $265(17.4)$ & $203(18.0)$ & $83(21.1)$ & \\
\hline $15-17$ & $1335(43.8)$ & $722(47.4)$ & $455(40.2)$ & $158(40.2)$ & \\
\hline $18-20$ & $816(26.8)$ & $427(28.0)$ & $286(25.3)$ & $103(26.2)$ & \\
\hline$\geq 21$ & $317(10.4)$ & $100 \quad(6.6)$ & $172(15.2)$ & $45(11.5)$ & \\
\hline Missing/not available & $28 \quad(0.9)$ & $9(0.6)$ & $15(1.3)$ & $4(1.0)$ & \\
\hline \multicolumn{5}{|l|}{ Ever had oral sex } & $<0.0001$ \\
\hline Yes & $2743(90.0)$ & $1415(92.9)$ & $1010(89.3)$ & $318(80.9)$ & \\
\hline No & $304(10.0)$ & $108(7.2)$ & $121(10.7)$ & $75(19.1)$ & \\
\hline \multicolumn{5}{|l|}{ Ever had anal sex } & $<0.0001$ \\
\hline Yes & $1514(49.7)$ & $674(44.3)$ & $648(57.3)$ & $192(48.9)$ & \\
\hline No & $1513(49.7)$ & $840(55.2)$ & $475(42.0)$ & $198(50.4)$ & \\
\hline Unknown/refused & $20(0.7)$ & $9(0.6)$ & $8 \quad(0.7)$ & $3(0.8)$ & \\
\hline \multicolumn{5}{|c|}{ Ever exchanged sex for money or drugs } & 0.0001 \\
\hline Yes & $328(10.8)$ & $134(8.8)$ & $157(13.9)$ & $37(9.4)$ & \\
\hline No & $2707(88.8)$ & $1384(90.9)$ & $971(85.9)$ & $352(89.6)$ & \\
\hline Unknown/refused & $12(0.4)$ & $5 \quad(0.3)$ & $3(0.3)$ & $4(1.0)$ & \\
\hline \multicolumn{5}{|c|}{ Condom use with vaginal sex in recent past } & $<0.0001$ \\
\hline No vaginal sex in recent past & $221(7.3)$ & $114(7.5)$ & $57 \quad(5.0)$ & $50(12.7)$ & \\
\hline Never & $1123(36.9)$ & $372(24.4)$ & $532(47.0)$ & $219(55.7)$ & \\
\hline Sometimes & $1054(34.6)$ & $654(42.9)$ & $342(30.2)$ & $58(14.8)$ & \\
\hline Always & $610(20.0)$ & $368(24.2)$ & $189(16.7)$ & $53(13.5)$ & \\
\hline Unknown/refused & $39(1.3)$ & $15(1.0)$ & $11(1.0)$ & $13(3.3)$ & \\
\hline \multicolumn{5}{|l|}{ Lifetime female sexual partners $(n)$} & $<0.0001$ \\
\hline 1 & $283 \quad(9.3)$ & $201(13.2)$ & $69(6.1)$ & $13(3.3)$ & \\
\hline $2-9$ & $1381(45.3)$ & $804(52.8)$ & $455(40.2)$ & $122(31.0)$ & \\
\hline $10-19$ & $546(17.9)$ & $236(15.5)$ & $229(20.3)$ & 81 (20.6) & \\
\hline $20-49$ & $492(16.1)$ & $180(11.8)$ & $211(18.7)$ & $101(25.7)$ & \\
\hline$\geq 50$ & 179 & $44 \quad(2.9)$ & $92(8.1)$ & $43(10.9)$ & \\
\hline Unknown/refused & $166 \quad(5.5)$ & $58 \quad(3.8)$ & 75 (6.6) & $33(8.4)$ & \\
\hline
\end{tabular}

*Percentages may not total to 100 due to rounding. 
Table 3 Adjusted estimates of the likelihood of a positive test for a sexually transmitted infection by age cohort*

\begin{tabular}{|c|c|c|c|c|}
\hline Characteristic & $\begin{array}{l}\text { Total } \\
(N=3047) \\
\text { AOR }(95 \% \mathrm{Cl}) \dagger\end{array}$ & $\begin{array}{l}18-30 \text { years } \\
(N=1523) \\
\text { AOR }(95 \% \mathrm{Cl}) \dagger\end{array}$ & $\begin{array}{l}31-44 \text { years } \\
(N=1131) \\
\text { AOR }(95 \% \mathrm{Cl}) \dagger\end{array}$ & $\begin{array}{l}45-70 \text { years } \\
(N=393) \\
\text { AOR }(95 \% \mathrm{Cl}) \dagger\end{array}$ \\
\hline \multicolumn{5}{|l|}{ Age (years) } \\
\hline $18-30$ & $0.29(0.20-0.40)$ & \multirow[t]{3}{*}{$\ddagger$} & \multirow[t]{3}{*}{$\ddagger$} & \multirow[t]{3}{*}{$\ddagger$} \\
\hline $31-44$ & $0.74(0.55-0.98)$ & & & \\
\hline $45-70$ & Referent & & & \\
\hline \multicolumn{5}{|l|}{ Country of residence } \\
\hline Brazil & $3.00(2.14-4.20)$ & 7.47 (3.91-14.30) & $1.75(1.03-2.95)$ & $2.25(1.03-4.89)$ \\
\hline Mexico & $0.55 \quad(0.27-1.14)$ & $0.71 \quad(0.21-2.41)$ & $0.36(0.13-1.03)$ & $1.09(0.14-8.31)$ \\
\hline USA & Referent & Referent & Referent & Referent \\
\hline \multicolumn{5}{|l|}{ Race } \\
\hline White & Referent & Referent & Referent & Referent \\
\hline Black & $1.50(1.15-1.96)$ & $1.07 \quad(0.67-1.72)$ & $1.64(1.10-2.42)$ & $1.48(0.76-2.87)$ \\
\hline Asian/Pacific Islander & $0.81(0.38-1.74)$ & $(0.13-1.67)$ & $1.67(0.51-5.43)$ & $\S$ \\
\hline American Indian/Alaskan & $0.80(0.43-1.48)$ & $(0.21-1.87)$ & $1.20(0.53-2.72)$ & $0.23(0.04-1.40)$ \\
\hline Mixed & $1.30(0.67-2.50)$ & $1.67 \quad(0.55-5.09)$ & $1.24(0.49-3.10)$ & $0.65(0.10-4.33)$ \\
\hline \multicolumn{5}{|l|}{ Marital status } \\
\hline Single & $0.93(0.69-1.25)$ & $1.00 \quad(0.58-1.73)$ & $0.96(0.63-1.47)$ & $1.73 \quad(0.74-4.08)$ \\
\hline Married & Referent & Referent & Referent & Referent \\
\hline Cohabitating & $1.06(0.77-1.46)$ & $1.15 \quad(0.61-2.19)$ & $0.93(0.61-1.43)$ & $1.34 \quad(0.59-3.07)$ \\
\hline Divorced/separated/widowed & $1.46(1.04-2.06)$ & $1.68 \quad(0.61-4.62)$ & $1.91(1.21-3.02)$ & $0.83 \quad(0.43-1.62)$ \\
\hline \multicolumn{5}{|l|}{ Educational level (years) } \\
\hline$<12$ & $1.62(1.01-2.59)$ & $0.53 \quad(0.20-1.38)$ & $3.04(1.53-6.06)$ & $1.03(0.39-2.72)$ \\
\hline 12 & $1.25(0.79-1.96)$ & $0.44 \quad(0.18-1.07)$ & $1.85(0.95-3.59)$ & $1.33(0.50-3.55)$ \\
\hline $13-15$ & $1.25(0.79-1.99)$ & $0.41 \quad(0.17-1.02)$ & $2.85(1.43-5.68)$ & $1.07(0.42-2.70)$ \\
\hline 16 & $1.15(0.72-1.82)$ & $0.37 \quad(0.15-0.92)$ & $1.82(0.92-3.62)$ & $0.88 \quad(0.34-2.25)$ \\
\hline$\geq 17$ & Referent & Referent & Referent & Referent \\
\hline \multicolumn{5}{|l|}{ Age at first vaginal sex (years) } \\
\hline$\leq 14$ & $2.15(1.43-3.23)$ & $(0.55-2.79)$ & $2.37(1.34-4.18)$ & $3.75(1.45-9.74)$ \\
\hline $15-17$ & $1.11(0.76-1.62)$ & $0.67 \quad(0.31-1.44)$ & $1.28(0.76-2.14)$ & $1.42(0.60-3.37)$ \\
\hline $18-20$ & $1.28(0.87-1.89)$ & $0.81 \quad(0.37-1.79)$ & $1.80(1.05-3.07)$ & $1.08(0.44-2.68)$ \\
\hline$\geq 21$ & Referent & Referent & Referent & Referent \\
\hline \multicolumn{5}{|c|}{ Ever exchanged sex for money or drugs } \\
\hline Yes & $1.35(1.01-1.80)$ & $1.01 \quad(0.59-1.72)$ & $1.18(0.78-1.78)$ & $2.30(1.05-5.04)$ \\
\hline No & Referent & Referent & Referent & Referent \\
\hline \multicolumn{5}{|l|}{ Lifetime female sexual partners $(n)$} \\
\hline 1 & Referent & Referent & Referent & Referent \\
\hline $2-9$ & $1.04(0.75-1.46)$ & $1.19 \quad(0.67-2.11)$ & $1.13(0.68-1.90)$ & $0.65(0.29-1.49)$ \\
\hline $10-19$ & $1.02(0.70-1.49)$ & $(0.37-1.60)$ & $1.14(0.65-2.00)$ & $0.80 \quad(0.33-1.90)$ \\
\hline $20-49$ & $1.48(1.02-2.16)$ & $2.06 \quad(1.04-4.06)$ & $1.48(0.83-2.63)$ & $0.47 \quad(0.20-1.13)$ \\
\hline$\geq 50$ & $2.07(1.31-3.28)$ & $4.33(1.74-10.76)$ & $1.34(0.68-2.65)$ & $1.04 \quad(0.38-2.84)$ \\
\hline
\end{tabular}

*Outcome is composite sexually transmitted infection variable: testing positive for genital herpes, chlamydia, gonorrhoea and/or syphilis.

Model is adjusted for the following variables: country of residence, race, ethnicity/Hispanic, marital status, educational level, circumcision status, age at first vaginal sex, previous oral sex and anal sex activity, condom use, and number of lifetime female sexual partners. Ethnicity/Hispanic, circumcision status, previous oral and anal sex activity, and condom use are not included in the table due to lack of significant findings.

†AOR, adjusted odds ratio; $95 \% \mathrm{Cl}, 95 \%$ confidence interval. Significant values in bold font.

‡Not applicable.

§lnsufficient cell size.

cohort of men, young adult men and middle-aged men both have reduced odds for a positive STI test [adjusted OR $(\mathrm{AOR})=0.29,95 \%$ CI $0.20-0.40$ and $\mathrm{AOR}=0.74, \quad 95 \% \quad \mathrm{CI} \quad 0.55-0.98$, respectively). Overall, Brazilian men had the highest risk of testing positive for an STI (AOR=3.00, 95\% CI 2.14-4.20).
Black men in the study sample were nearly 1.5 times more likely to test positive for an STI $(\mathrm{AOR}=1.50$, 95\% CI 1.15-1.96), relative to white participants. Men who were divorced, separated or widowed were also 1.5 times more likely to test positive for an STI, as compared to married men $(\mathrm{AOR}=1.46,95 \% \mathrm{CI}$ 
1.04-2.06). Men who did not complete secondary education were at increased sexual risk, relative to men with advanced levels of education $(\mathrm{AOR}=1.62$, 95\% CI 1.01-2.59). Additionally, early age of sexual debut was associated with a more than two-fold heightened risk for a positive STI test $(\mathrm{AOR}=2.15$, 95\% CI 1.43-3.23). Experiences exchanging sex for money or drugs was found to elevate sexual risk in the general study sample $(\mathrm{AOR}=1.35$, 95\% CI 1.011.80). Higher numbers of lifetime sexual partners intensified the risk of a positive STI test in the study sample (20-49 partners: AOR $=1.48,95 \%$ CI 1.0 2.16; $\geq 50$ partners: $\mathrm{AOR}=2.07,95 \%$ CI $1.31-3.28)$.

Within the youngest cohort (18-30 years), Brazilian men had a more than seven-fold risk for testing positive for an STI (AOR=7.47, 95\% CI 3.91-14.30), compared to men in the USA. Advanced levels of education were found to be protective for testing positive for an STI among young men (16 years: AOR $=0.37$, 95\% CI 0.15-0.92), whereas young men with larger numbers of lifetime sexual partners had a two- to four-fold increased risk (20-49 partners: AOR $=2.06$, 95\% CI 1.04-4.06; $\geq 50$ partners: $\mathrm{AOR}=4.33,95 \%$ CI 1.74-10.76).

Multiple variables amplified sexual risk for middle-aged men (31-44 years) (Table 3). Black men in this age group had $64 \%$ increased odds of testing positive for an STI (AOR=1.64, 95\% CI 1.10-2.42), whereas men in the study population who were divorced, separated or widowed had a 91\% elevated risk $(\mathrm{AOR}=1.91,95 \%$ CI 1.21-3.02). Both a lower and a higher level of formal education $(<12$ years: $\mathrm{AOR}=3.04, \quad 95 \% \quad \mathrm{CI} \quad 1.53-6.06 ; \quad 13-15$ years: $\mathrm{AOR}=2.85,95 \% \mathrm{CI} 1.43-5.68$ ) were found to amplify sexual risk by nearly three times. Similarly, early and older ages at sexual initiation $(<14$ years: $\mathrm{AOR}=2.37$, 95\% CI $1.34-4.18 ; 18-20$ years: AOR $=1.80,95 \%$ CI 1.05-3.07) were associated with a higher likelihood of STI positivity.

Within the study's oldest cohort (45-70 years old), men living in Brazil (AOR=2.25; 95\% CI 1.03-4.89) and those who reported previously exchanging sex for money or drugs $(\mathrm{AOR}=2.30,95 \%$ CI $1.05-5.04)$ had a more than two-fold increased risk of testing positive for an STI. Furthermore, older men who first had sexual intercourse at the age of 14 years or younger had a nearly four-fold elevated sexual risk $(\mathrm{AOR}=3.75,95 \%$ CI 1.45-9.74).

\section{DISCUSSION}

Our study found that STI positivity varied significantly by age group among heterosexual men. In younger men, having higher educational levels had a protective effect, whereas higher numbers of sexual partners elevated the risk for STIs. Middle-aged men who were black and divorced/separated/widowed had an increased risk for a positive STI test. Middle-aged men with less than a secondary level education
( $<12$ years) and some college education (13-15 years) were found to have elevated sexual risk, and those who had an early age of sexual debut ( $\leq 14$ years) and young adult onset of sexual activity (18-20 years) had higher risk estimates for a positive STI test. For older men, a younger age at first vaginal sexual encounter and a history of exchanging sex for money or drugs heightened sexual risk.

Our study has important public health implications. Most research studies examining sexual behaviour have been conducted with adolescents and young adults; ${ }^{6-8}$ however, sexual risk-taking and STI transmission among older adults is now recognised as a growing public health problem. ${ }^{12-14}$ Therefore, our examination of risk and protective factors for sexual risk by age cohort, inclusive of men aged $18-70$ years, fills an important gap in the literature. Few sexual research studies have investigated factors related to heterosexual men. ${ }^{1}{ }^{3-5}$ Consequently, our study provides information that may be beneficial for interventions to prevent and reduce the heterosexual transmission of STIs across age groups. More specifically, our results suggest that age cohort is a key factor in the development and implementation of targeted approaches for STI prevention among men.

In our analysis, we identified multiple protective and risk factors for STIs among heterosexual men that reinforce previous research findings. Numerous studies have consistently shown that paid sex increases the risk for HIV and other STIs. ${ }^{24-26}$ The present study provides further evidence of this assertion, as there was a $35 \%$ increased risk for STIs among men who reported ever exchanging sex for money or drugs. Our study also found that young men with higher numbers of lifetime sexual partners had a two- to four-fold heightened risk for a positive STI test. Similarly, previous research has observed a relationship between an increasing number of sexual partners and the risk of STIs. ${ }^{27}{ }^{28}$ Early sexual debut was associated with a more than two-fold elevated risk of STIs in our study sample, which was amplified among middle-aged and older adult males. Our findings support those from multiple studies that have determined that young age at sexual initiation increases likelihood of HIV and STI transmission among men; ${ }^{8} 2728$ however, most of these prior studies were conducted with adolescents or young adults.

There are some potential limitations in this study. As we utilised an existing dataset, we were restricted in the variables considered in the examination of sexual behaviours and risk among heterosexual men. Within this secondary dataset, some of the variables considered in this analysis were based on self-reported data, which may be affected by recall bias. Particularly because this study addresses highly sensitive information and practices (i.e. sexual behaviours and history), there is a possibility of social desirability bias in the manner in which participants responded to survey items. However, the use of CASI has been shown to 
decrease the possibility of biased information being collected and improving the validity of study findings, particularly in sexual behaviour research. ${ }^{29-31}$ Furthermore, we have previously found that the utilisation of CASI in the data collection process for the parent study (i.e. the HIM Study) demonstrated high reliability in response to sensitive sexual behaviour questions. ${ }^{16}$

Despite these limitations, this study has some noteworthy strengths. The study sample size is sufficient to offer substantial power for the detection of group variances in the analysis. Although we cannot exclude the possibility of residual confounding due to unmeasured variables, we controlled for several potential confounders in our statistical analysis. The sub-analysis conducted by age cohort yields important information on the age-related variances in sexual behaviours and risk.

Due to the dearth of studies on sexual risk among heterosexual men, continued research is needed regarding sexual behaviours within this population, particularly among older age groups. Our study findings highlight the need for added public health efforts to reduce STI risk and transmission among heterosexual men beyond the adolescent period. Determining which male subpopulations have an increased risk of STI infection and understanding trend patterns over time is helpful in allocating resources for effective prevention, treatment and management necessary for curtailing STI transmission. Moreover, information on the prevalence of sexual behaviours by socio-demographic characteristics is beneficial in the development and implementation of relevant policies and interventions to reduce STI prevalence, increase awareness, and improve quality of life.

\footnotetext{
Author affiliations

${ }^{1}$ Research Coordinator, Department of Community and Family Health, College of Public Health, University of South Florida, Tampa, FL, USA

${ }^{2}$ Associate Professor, Department of Community and Family Health, College of Public Health, University of South Florida, Tampa, FL, USA

${ }^{3}$ Professor, Department of Educational Measurement and Research, College of Education, University of South Florida, Tampa, FL, USA

${ }^{4}$ Professor, Department of Community and Family Health, College of Public Health, University of South Florida, Tampa, FL, USA

${ }^{5}$ Associate Professor, Department of Anthropology, College of Arts and Sciences, University of South Florida, Tampa, FL, USA

${ }^{6}$ Professor, Unidad de Investigación Epidemiológica en Servicios de Salud, Instituto Mexicano del Seguro Social, Cuernavaca, Morelos, México

${ }^{7}$ Director, Centro de Investigación Salud Poblacional, Instituto Nacional de Salud Pública, Cuernavaca, Morelos, México

${ }^{8}$ Professor, Faculty of Medical Sciences of Santa Casa of São Paulo, São Paulo, Brazil
}

${ }^{9}$ Distinguished Professor, Department of Community and Family Health, College of Public Health, University of South Florida, Tampa, FL, USA ${ }^{10}$ Director, Center for Infection Research in Cancer, $\mathrm{H}$ Lee Moffitt Cancer Center and Research Institute, Tampa, FL, USA

\section{Competing interests None.}

Ethics approval This investigation was approved by the Institutional Review Board of the University of South Florida.

Provenance and peer review Not commissioned; externally peer reviewed.

\section{REFERENCES}

1 Aidala AA, Lee G, Howard JM, et al. HIV-positive men sexually active with women: sexual behaviors and sexual risks. J Urban Health 2006;83:637-655.

2 Exner TM, Gardos PS, Seal DW, et al. HIV sexual risk reduction interventions with heterosexual men: the forgotten group. AIDS Behav 1999;3:347-358.

3 Seal DW, Ehrhardt AA. HIV-prevention-related sexual health promotion for heterosexual men in the United States: pitfalls and recommendations. Arch Sex Behav 2004;33:211-222.

4 Dworkin SL, Fullilove RE, Peacock D. Are HIV/AIDS prevention interventions for heterosexually active men in the United States gender-specific? Am J Public Health 2009;99:981-984.

5 Higgins JA, Hoffman S, Dworkin SL. Rethinking gender, heterosexual men, and women's vulnerability to HIV/AIDS. Am J Public Health 2010;100:435-445.

6 Makenzius M, Gadin KG, Tyden T, et al. Male students' behaviour, knowledge, attitudes, and needs in sexual and reproductive health matters. Eur J Contracept Reprod Health Care 2009;14:268-276.

7 Mooney-Somers J, Ussher JM. Sex as commodity: single and partnered men's subjectification as heterosexual men. Men Masculinities 2008;12:353-373.

8 Sandfort TGM, Orr M, Hirsch JS, et al. Long-term health correlates of timing of sexual debut: results from a national US study. Am J Public Health 2008;98:155-161.

9 LaBrie JW, Pedersen ER, Thompson AD, et al. A brief decisional balance intervention increases motivation and behavior regarding condom use in high-risk heterosexual college men. Arch Sex Behav 2008;37:330-339.

10 Noar SM, Morokoff PJ, Redding CA. An examination of transtheoretical predictors of condom use in late-adolescent heterosexual men. J Appl Biobehav Res 2001;6:1-26.

11 Tan HH, Wong ML, Chan RK. An epidemiological and knowledge, attitudes, beliefs and practices study of sexually transmitted infections in older men. Singapore Med J 2006;47:886-891.

12 Coleman CL, Ball K. Determinants of perceived barriers to condom use among HIV-infected middle-aged and older African-American men. J Adv Nurs 2007;60:368-376.

13 Kohli R, Klein R, Schoenbaum E, et al. Aging and HIV infection. J Urban Health 2006;83:31-42.

14 Savasta AM. HIV: associated transmission risks in older adults - an integrative review of the literature. J Assoc Nurses AIDS Care 2004;15:50-59.

15 Stall R, Catania J. AIDS risk behaviors among late middle-aged and elderly Americans: the national AIDS behavioral surveys. Arch Intern Med 1994;154:57-63. 
16 Nyitray AG, Kim J, Hsu CH, et al. Test-retest reliability of a sexual behavior interview for men residing in Brazil, Mexico, and the United States: the HPV in Men (HIM) Study. Am J Epidemiol 2009;170:965-974.

17 Giuliano AR, Lee JH, Fulp W, et al. Incidence and clearance of genital human papillomavirus infection in men (HIM): a cohort study. Lancet 2011;377:932-940.

18 Beck A, McNally I, Petrak J. Psychosocial predictors of HIV/ STI risk behaviours in a sample of homosexual men. Sex Transm Infect 2003;79:142-146.

19 Kirby DB, Laris BA, Rolleri LA. Sex and HIV education programs: their impact on sexual behaviors of young people throughout the world. J Adolesc Health 2007;40:206-217.

20 Slaymaker E, Walker N, Zaba B, et al. Unsafe sex. In: Ezzati M, Lopez AD, Rodgers A, Murray CJL (eds), Comparative Quantification of Health Risks: Global and Regional Burden of Diseases Attributable to Selected Major Risk Factors (Vols 1-3). Geneva, Switzerland: World Health Organization, 2005:1177-1254.

21 Akogbe GO, Ajidahun A, Sirak B, et al. Race and prevalence of human papillomavirus infection among men residing in Brazil, Mexico and the United States. Int J Cancer 2012:131:E282E291.doi:10.1002/ijc.27397 [published Online First: Epub date 11 January 2012].

22 Nyitray AG, Carvalho da Silva RJ, Baggio ML, et al. Age-specific prevalence of and risk factors for anal human papillomavirus (HPV) among men who have sex with women and men who have sex with men: the HPV in men (HIM) study. J Infect Dis 2011;203:49-57.

23 Nyitray AG, Smith D, Villa L, et al. Prevalence of and risk factors for anal human papillomavirus infection in men who have sex with women: a cross-national study. J Infect Dis 2010;201:1498-1508.

24 Chen L, Jha P, Stirling B, et al. Sexual risk factors for HIV infection in early and advanced HIV epidemics in sub-Saharan Africa: systematic overview of 68 epidemiological studies. PLoS One 2007;2:e1001.

25 Mimiaga M, Reisner S, Tinsley J, et al. Street workers and internet escorts: contextual and psychosocial factors surrounding HIV risk behavior among men who engage in sex work with other men. J Urban Health 2009;86:54-66.

26 Patterson TL, Goldenberg S, Gallardo M, et al. Correlates of HIV, sexually transmitted infections, and associated high-risk behaviors among male clients of female sex workers in Tijuana, Mexico. AIDS 2009;23:1765-1771.

$27 \mathrm{Lu} \mathrm{B}$, Wu Y, Nielson CM, et al. Factors associated with acquisition and clearance of human papillomavirus infection in a cohort of US men: a prospective study. J Infect Dis 2009;199:362-371.

28 Nielson CM, Harris RB, Dunne EF, et al. Risk factors for anogenital human papillomavirus infection in men. J Infect Dis 2007;196:1137-1145.

29 Fenton KA, Johnson AM, McManus S, et al. Measuring sexual behaviour: methodological challenges in survey research. Sex Transm Infect 2001;77:84-92.

30 Ghanem KG, Hutton HE, Zenilman JM, et al. Audio computer assisted self interview and face to face interview modes in assessing response bias among STD clinic patients. Sex Transm Infect 2005;81:421-425.

31 Kurth AE, Martin DP, Golden MR, et al. A comparison between audio computer-assisted self-interviews and clinician interviews for obtaining the sexual history. Sex Transm Dis 2004;31:719-726. 